\title{
Inflation Targeting Monetary Policy Rule in Nigeria: Estimates of the Policy Reaction Function
}

\author{
Apanisile Olumuyiwa Tolulope $^{1} \&$ Taiwo Ajilore ${ }^{1}$ \\ ${ }^{1}$ Department of Economics, Obafemi Awolowo University, Ile-Ife, Nigeria \\ Correspondence: Apanisile Olumuyiwa Tolulope, Department of Economics, Obafemi Awolowo University, \\ Ile-Ife, Nigeria. Tel: 234-703-193-5974. E-mail: tolumid@yahoo.com
}

Received: November 9, 2012

Accepted: May 2, $2013 \quad$ Online Published: June 20, 2013

doi:10.5539/ijef.v5n7p139

URL: http://dx.doi.org/10.5539/ijef.v5n7p139

\begin{abstract}
Inflation Targeting Monetary Policy stance of Nigeria was examined using Taylor Policy Rule. The study used quarterly data from 2000:1 to 2010:4. Engle- Granger approach to co-integration was adopted and the results showed that implementation of monetary policy function was effectively done in order to achieve price stability in the economy that is characterized with persistent inflation for a very long time. The study therefore concluded that, monetary policy, in Nigeria context, needed to be supported by contractionary fiscal policy so as to be able to achieve the desired objectives.
\end{abstract}

Keywords: monetary policy, inflation targeting, engle-granger approach

\section{Introduction}

There are various approaches through which monetary policy could be conducted in order to achieve the desired goals of macroeconomic management. Two of the major approaches usually adopted for the conduct of monetary policy are monetary targeting approach and inflation targeting approach. Monetary targeting approach involves the use of open market operations to control money supply into the economy. Inflation targeting approach on the other hand, involves the use of interest rate as the policy instrument to containing inflation within the target band. Whenever inflation is going out of the band, interest rate is increased so as to bring it back within the band.

Inflation targeting approach has some advantages which makes it to be considered in the recent times above other methods of conducting monetary policy in different economies. These includes: preservation of central bank's discretion in reacting to the prevailing conditions of a country in different ways and allowance of adjustment in the exchange rate to stabilize external influence (Casteleijn, 1999, Jonsson, 1999, Mboweni, 2002, Woglom, 2003).

Monetary policy conduct in the late 1970s and early 1980s was based on explicit monetary aggregates targets. However, subsequent reforms in the financial sector occasioned rapid development in the financial markets, causing the money demand function to be increasingly unstable. This had adverse effect on the relationship between money and prices and further complicating forecasts of money demand. Thus, the use of monetary targeting approach became more difficult. In view of this, the Central Bank of Nigeria abandoned the monetary targeting framework for its operation and switched over to an implicit inflation targeting approach in the year 2000. The monetary policy was targeted at keeping inflation rate within 8.5 percent. In order to achieve this, the interest rate served as the policy instrument for bringing inflation within targets so that if the rate of inflation exceeded the 8.5 percent target, the Central Bank would increase the official lending rate in order to bring inflation back to the target. Despite this inflation targeting monetary policy framework, evidence had cast doubts on the effectiveness of this structure in achieving the desired objective.

A wide deviations of inflation performance from its target bound was clearly evident from figure1, casting doubts on the effectiveness of the inflation targeting monetary policy framework in Nigeria. Then, it becomes imperative for this work to specify and estimate policy reaction function of the Central Bank of Nigeria in order to ascertain how well it tracked the theoretical Taylor's rule that underpins the inflation targeting monetary policy function framework in the Nigeria context. Following this introduction, the rest of the paper is arranged thus: Section 2 gives consideration to the theoretical underpinnings and the review of the related literatures. Section 3 deals with model specification and data measurements. Section 4 presents and discusses the results of 
findings and Section 5 concludes with implications for monetary policy management in Nigeria.

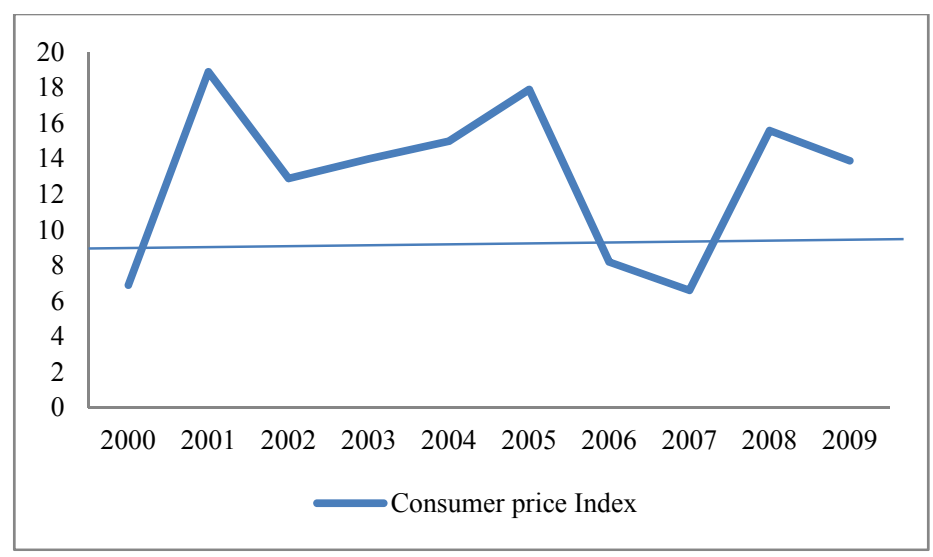

Figure 1. Consumer price index 2000-2010

Source: CBN Statistical Bulletin 2010.

\section{Theoretical Framework and Review of Related Literature}

There are various types of policy rules that are embedded in the discussion of monetary policy rules. The two most relevant of these rules to this study are rules for policy targets and rules for policy instruments. A rule for a policy instrument specifies how the central bank will determine the value of its policy instrument, in most cases a short-run interest rate. A rule for the policy target specifies the objectives of monetary policy. Fixed exchange rate, which is one of the objectives of monetary policy, could only be attained when the replacement of monetary policy tool is done as a result of the desire to achieve the set goal. Therefore, controlling inflation rate in an economy is imperative for the achievement of monetary policy objectives (woglom, 2003). Reducing the rate of inflation in an economy can be achieved through implementation of monetary policy rules that guides policy instrument or depending of policy makers discretion as is the case in Nigeria.

The monetary policy that adopts interest rate as policy instrument, is often stated in the form of a Taylor rule (Taylor, 1993, 1999). This is due to the ability of Taylor rule in revealing the performance of inflation $(\pi)$ and output gap (y) in an economy. The non-stability nature of inflation and output gap in most economies, as detected by Taylor rule, enables central bank to change its policy rate (R) target. In the face of this feedback rule, the central bank would increase its benchmark if actual output (or the demand for it) were too high or if inflation were too high, relative to their long-run or desired levels. Such a policy is sometimes depicted as one of "leaning against the wind". Taylor (1999) showed that differences in the CBN's tool for achieving its objective can be captured using a multivariate regression as depicted in equation (1) below:

$$
\boldsymbol{R}_{t}=\alpha_{o}+\alpha_{1} \boldsymbol{R}_{t-1}+\alpha_{2} \widehat{\boldsymbol{y}}_{t-1}+\alpha_{3} \pi_{t-1}+\mu_{t}
$$

Where $\mathrm{R}$ is a short-term nominal interest rate, $\pi$ is a measure of inflation and $\hat{y}$ is a measure of the output gap. Given the price stability and full employment pursuits of the Central bank, one would expect that $\alpha_{2}>0$ and $\alpha_{3}<0$. The lagged interest rate appears in (1) because of the tendency of central banks to try to smooth fluctuations in their policy instrument. With the presence of the lagged interest rate, the long run effect of an increase in inflation on the policy instrument is $\alpha_{3} /\left(1-\alpha_{1}\right)$. For achieving stability in the rate of inflation in the future, it is expected that the nominal interest rate response to inflation should exceed one. An issue actively pursued in further research on the Taylor rule has been whether or not exchange rate $(\varepsilon)$ should be included in this rule. The argument in favour of their inclusion is that shifts in them can change aggregate demand. Laurence Ball (2000), justified the inclusion of real exchange rate in Taylor rule specification for an economy that engages in both regional and international trade. Doing so yields extended forms of the Taylor rule. Many empirical studies report that using some form of an augmented Taylor rule, such as incorporating changes in wealth or house prices or exchange rates leads to greater stabilization of the economy. Ncube and Mthokozisi (2010) argued that addition of real exchange rate to the original Taylor rule would aid the analysis of interest rate response to changes in real exchange rate.

Similarly, Taylor (2000) revealed that there exist a relationship between interest rate and the exchange rate through capital markets. Based on the foregoing, the CBN's policy reaction function of the Taylor rule type, where observable short term nominal interest rate is determined as follows: 


$$
\boldsymbol{R}_{t}=\alpha_{o}+\alpha_{1} \boldsymbol{R}_{t-1}+\alpha_{2} \widehat{y}_{t-1}+\alpha_{3} \pi_{t-1}+\alpha_{4} \varepsilon_{t-1}+\mu_{t}
$$

Where $\varepsilon$ is the real appreciation of the currency. Theory suggests that $\alpha_{4}$ should be negative for two reasons: first, depreciations will feed through to inflation and therefore will require a contractionary monetary policy response. Secondly, in open economies, a major way that monetary policy is transmitted to the real economy is through changes in the exchange rate, thus, a real depreciation is associated with expansionary monetary policy.

Several attempts had been made at analyzing the effects of inflation targeting approach of monetary policy on macroeconomic variables. Choi et al (2003) analyzed macroeconomic effects of inflation targeting policy in New Zealand using Markov switching model with one time permanent break. The sample period is from the first quarter of 1982 to the last quarter of 1996. The study estimated AR(2) model for the inflation rate of New Zealand because the Akaike's Information Criterion (AIC) and the Schwarz's Information Criterion (SIC) suggested that the series follows an auto-correlated process with two lags. The results showed that the inflation targeting policy has significantly changed the inflation dynamics in the New Zealand economy. The Markov switching model clearly detects a structural break date that is very close to the actual date of the policy change. The volatility in the inflation rate shows a considerable reduction after the structural break date. Also, the results showed that the inflation targeting policy led to a structural change in real GDP growth rate. The policy change significantly reduced the volatility of real GDP growth rate after the break date. This showed that there is a lag of about one year and six months between the monetary policy change and its actual effect on output growth.

Takeshi and Shigeyuki (2009) conducted an empirical analysis of the monetary policy reaction function in India by applying Taylor rule (1993) version which employs dynamic OLS. Monthly data, which spanned from April 1998 to December 2007 was employed. The results showed that output gap was statistically significant and it was in line with the theory but the story was not the same for inflation coefficient. The introduction of exchange rate into the original Taylor rule model did not change the result of output gap and exchange rate as their coefficients were both were significant. For inflation coefficient, the result did not change as the coefficient stay put. This implied inflation rate is not significant in India's economy and adopting inflation targeting approach for policy conduct in such economy is ineffectual.

Naraidooa and Guptab (2009) examined monetary policy modeling in South Africa using simple empirical nonlinear framework between 1983 and 2007. The study found out that modeling 'inflation learning rule' into its future policy plans gives better understanding of the actions of SARB. Results further revealed that implementation of inflation targeting monetary policy brought about drastic changes in the country's policy conduct and that the farther away an inflation rate is from its target, the more it responds became unpredictable. Furthermore, monetary policy in the subsequent years after 2000 is asymmetric because discrepancy between the target and actual inflation rate recorded higher responses from the policy makers. And lastly, policy makers in the post 2000 were working on keeping inflation slightly above the target band i.e. $4.5 \%-6.9 \%$ rather than 3-6\%.

Gerlach and Tillmann (2011) examined the effect of inflation targeting on inflation persistence in Asia Pacific from 1985-2010. The study used quarterly data from 1985:1 to 2010:1 and it is generated from the IMF's International Financial Statistics database. Countries included in the study are: Indonesia, Korea, the Philippines and Thailand. They adopted inflation targeting approach for their monetary policy conduct. The study also presented estimates for China, Taiwan POC, Japan, Malaysia and Singapore that gear monetary policy to price stability without relying on inflation targeting. The study explored the thriving rate of the strategy by examining the dominance of inflation in these countries, as measured by the sum of the coefficients in an autoregressive model for inflation, using a median unbiased estimator and bootstrapped confidence bands. The result showed that implementation of inflation targeting approach has reduced inflation drastically and that the rate of reduction is not the same among nations. It is exciting to note that countries that do not embrace inflation targeting have no sign of fall in inflation dominance. Therefore, the use of inflation dominance rather than inflation rate revealed above average performance of inflation targeting above other methods.

\section{Model Specification, Data and Estimation Techniques}

The study estimates the policy reaction function of the Taylor rule type espoused in Equation (2) above using Engle - Granger approach to co-integration. The estimation technique, as suggested by Engle and Granger (1987), involves a two-step estimation procedure. The first step involves regression analysis of equation (2) above in order to estimate the error term. The residual is generated as follows:

$$
\mu_{t}=R_{t}-\alpha_{o}-\alpha_{1} R_{t-1}-\alpha_{2} \widehat{y}_{t-1}-\alpha_{3} \pi_{t-1}-\alpha_{4} \varepsilon_{t-1}
$$

The residual generated in equation (3) above is a measure of disequilibrium. A test of co-integration is a test of whether $\mu_{\mathrm{t}}$ is stationary or not. This is determined by carrying out unit root test on the residual using Augmented 
Dickey-Fuller (ADF) with the MacKinnon (1990) critical values adjusted for the number of variables (which MacKinnon denotes as $n$ ). If the result is stationary after first differencing i.e. at $\mathrm{I}(1)$, then, there is co-integration. In this situation, equation (2) above is said to be super-consistent. This implies there is no need to include $\mathrm{I}(0)$ in the co-integrating equation. Based on this, an Error Correction Model (ECM) is constructed for the second step to characterize the short run disequilibrium situations and subsequent mean-reversion motions (Engle and Granger, 1987). The ECM takes the form:

$$
\Delta \boldsymbol{R}_{t}=\alpha_{o}+\sum_{j=1} \alpha_{j} \Delta \boldsymbol{R}_{t-j}+\sum_{h=1} \beta_{h} \widehat{\Delta y}_{t-h}+\sum_{i=1} \emptyset_{i} \Delta \pi_{t-i}+\sum_{g=1} \delta_{g} \varepsilon_{t-g}+\boldsymbol{\theta}_{t-1}+e_{t}
$$

According to the theory, the adjustment coefficient $\theta$ must be negative. Quarterly data series for Nigeria for the period 2000 (1) to 2010 (4) were used to estimate the models that are specified in this study. The choice of 2000 as a starting point for data is informed by the specific need to capture the inflation targeting monetary policy regime that started in Nigeria in 2000. All data series were obtained from CBN's Statistical Bulletin, 2010 except interest rate that was obtained fro World Development Indicators online source. To estimate the policy rule equation, real interest rate (R) was used. Output (y) is proxied by the Gross Domestic product (GDP). The real effective exchange rate was used as a proxy for the real appreciation of the currency, while the consumer price index (CPI) was used to measure prices $(\pi)$. The inflation target of 6 percentage points was used to construct the deviation of inflation from its target rate. An estimate of output gap variable $(\bar{y})$ is required to estimate the policy equation (Equation 2). This is constructed as the natural log of the ratio of trend output, $\mathrm{Y}_{\mathrm{T}}$, to real output, y. A real output trend was estimated, using a Hodrick-Prescott filter on the output data.

\section{Analysis of Data}

Unit root test on all variables was carried out using the Augmented Dickey-Fuller(ADF) and Phillip-Perron (PP) tests with intercept only in order to correct for non-stationarity nature of time series data. The result, as presented in table1 below, showed that all variables were non-stationary at levels. That is, they were not integrated at order zero but they became stationary after first differencing. The PP unit root test results as reported in Table 1 confirmed results from ADF test.

Table 1. Unit root test

\begin{tabular}{lllllll}
\hline \multicolumn{7}{l}{ Augmented Dickey-Fuller } \\
\hline Variables & Level & $1^{\text {st }}$ difference & Remarks & Level & $1^{\text {st }}$ difference & Remarks \\
\hline INFLATION & -3.156788 & $-3.732448^{*}$ & $\mathrm{I}(1)$ & -3.506130 & $-3.705929^{*}$ & $\mathrm{I}(1)$ \\
INTEREST RATE & -1.936856 & $-3.333920^{* *}$ & $\mathrm{I}(1)$ & -3.592759 & $-3.584602^{* *}$ & $\mathrm{I}(1)$ \\
OUTPUTGAP & -1.575005 & $-3.398331^{* *}$ & $\mathrm{I}(1)$ & -6.518947 & $-12.56725^{*}$ & $\mathrm{I}(1)$ \\
REXC & -1.570916 & $-6.238000^{*}$ & $\mathrm{I}(1)$ & -1.606956 & $-6.235144^{*}$ & $\mathrm{I}(1)$ \\
\hline
\end{tabular}

Notes: $* / * *$ represent stationary at land 5 percent level respectively.

Since all the variables are stationary of order one, i.e. I(1), the next step is to perform Engle-Granger Two step procedure for testing long-run co-integration. The first step is to estimate equation (2) using OLS. Engle-Granger states that if the variables are stationary of order one but the linear combination is stationarity of order zero, this implies the existence of long-run relationship among the variables; and according to the Engle Granger representation theorem, the presence of long-run relationship signifies the possibility of ECM (Error Correction Mechanism). Here, The long run OLS result is as follows:

$$
\begin{aligned}
& R_{t}=\mathbf{2 . 3 4 5 2}+0.7859 R_{t-1}+0.6781 \widehat{y}_{t-1}-0.0761 \pi_{t-1}-1.5547 \varepsilon_{t-1}+\mu_{t} \\
& \begin{array}{lllll}
(0.0287) & (0.0000) * & (0.2447) & (0.0159) * & (0.0128)^{*}
\end{array}
\end{aligned}
$$

* indicates $5 \%$ level of significance and () indicates probability value.

From this model, the residual (EC) is retrieved and ADF test with intercept is performed. The result showed that it is stationary at levels, that is $\mathrm{I}(0)$, as ADF test statistic with intercept is -6.398599 (5\% level critical value is -2.938987) and so from this test's result it can be said that the variables are co-integrated. According to Engle Granger representation theorem, there exists an ECM in the model and it is shown in the following table: 
Table 2. Estimates of Taylor rule monetary policy reaction function

\begin{tabular}{lll}
\hline Variable & Coefficient & p-value \\
\hline Constant & 2.696296 & 0.0212 \\
$\mathrm{ECM}_{\mathrm{t}-1}$ & -0.568160 & 0.0048 \\
$\mathrm{R}_{\mathrm{t}-1}$ & 0.634387 & 0.0000 \\
$\hat{y}_{\mathrm{t}-1}$ & 0.349207 & 0.5208 \\
$\pi_{\mathrm{t}-1}$ & -0.088396 & 0.0101 \\
$\varepsilon_{\mathrm{t}-1}$ & -0.009650 & 0.0113 \\
$\mathrm{R}^{2}$ & 0.74 & \\
Adj. $\mathrm{R}^{2}$ & 0.71 & \\
DW & 2.01 & \\
Prob(F-Statistic) & 0.00 & \\
\hline
\end{tabular}

From the table above, it can be deduced that all the variables, except output gap, are significant at $5 \%$ level of significant. The equation also shows a significant and correctly signed error correction term. This means all variables come back to their long- run equilibrium after a deviation in the past period. The equation also exhibits modest adjustment speed as indicated by the size (-0.56) of the coefficient of the error-correction term. This is less than unity and it implies that $56 \%$ of the equilibrium has been corrected in one year if there is a shock.

The result also shows a negative relationship between inflation and interest rate and also exchange rate and interest rate. This follows the a priori expectation that there exist an inverse relationship between interest rate and exchange rate and interest rate and inflation. Also, $\mathrm{R}^{2}$ implies $74 \%$ of changes in interest rates occur as a result of changes in the independent variable (output gap, inflation, exchange rate and lag of interest rate). The Durbin-Watson result which lies between 1.5 and 2.5 shows the absence of autocorrelation, that is, the error term is independent. Finally, F-statistic which shows the overall significance of all the variable is significant at both $1 \%$ and $5 \%$ by considering the probability value $(0.00)$ as depicted in the table.

\section{Conclusions}

The paper estimated a monetary policy reaction function for the Central Bank of Nigeria, using Taylor policy rule, so as to underpin the inflation targeting monetary policy function framework in the Nigeria context. This is because such a framework is useful in determining the path of monetary policy decision making by central banks.

The study adopted Engle-Granger approach to co-integration and discover that there exist long-run relationship among the variables. In order to correct for the short-run dynamics and explain the speed of adjustment, error correction was estimated. The error correction term was generated using the residual series of the OLS result.

The result shows that the monetary policy reaction function, in the context of Nigeria, is correctly specified in order to achieve low inflationary rate in Nigeria with the history of ridiculous inflation for some time. Hence, for price stability objective, using interest rate as instrument, to be achieved, government at all levels in the country are required to operate contractionary policy so as to reduce currency flow in the economy.

\section{References}

Ball, L. (2000). Policy Rules and External Shocks. NBER Working Paper 7910.

Casteleijn, A. (1999). The Viability of Implementing an Inflation Targeting Monetary Policy Framework in South Africa. South African Reserve Bank Quarterly Economic Review, June.

Engle, R., \& Granger, C. (1987). Co-Integration and Error Correction: Representation, Estimation, and Testing. Econometrica, 55(2). http://dx.doi.org/10.2307/1913236

Gerlach, S., \& Tillmann, P. (2011). Inflation Targeting and Inflation Persistence in Asia-Pacific. Hong Kong Institute for Monetary Research Working Paper No.25/2011.

Gujarati, D. N., \& Porter, D. C. (2009). Basic Econometrics International Edition.

Inder, B. (1986). An approximation to the Null Distribution of the Durbin-Watson Statistic in Models Containing Lagged Dependent Variables. Econometric Theory, 2(3), 413-428. http://dx.doi.org/10.1017/S0266466600011683

Jonsson, G. (1999). The Relative Merits and Implications of Inflation Targeting for South Africa. IMF Working Paper. 
Kiviet, J. F. (1986). On the Vigour of Some Misspecification Tests for Modeling Dynamic Relationships. Review of Economic Studies, 53(173), 241-262. http://dx.doi.org/10.2307/2297649

MacKinnon, J. (1990). Critical values for co-integration tests. UC San Diego: Economics Working Paper Series, No 90-4.

Mboweni, T. (2002). Governor's Address at the Bureau of Economic Research. South African Reserve Bank, 11 November.

Naraidooa, R., \& Gupta, R. (2009). Modeling Monetary Policy in South Africa: Focus on inflation Targeting Era Using a Simple Learning Rule. University of Pretoria, Department of Economics Working Paper Series, Working Paper: 2009-04 January 2009.

Ncube, M., \& Mthokozisi, T. M. (2010). Monetary Policy Conduct Based on Nonlinear Taylor Rule: Evidence from South Africa. Working Papers Series $\mathrm{N}^{\circ} 113$, African Development Bank, Tunis, Tunisia.

Nelson, C., \& Plosser, C. (1982). Trends and Random Walks in Macroeconomics Time Series: Some Evidence and Implications. Journal of Monetary Economics, 10, 139-162. http://dx.doi.org/10.1016/0304-3932(82)90012-5

Taylor, J. B. (1993). Discretion versus Policy Rules in Practice. Carnegie-Rochester Conference Series on Public Policy 39, December, 195-214. http://dx.doi.org/10.1016/0167-2231(93)90009-L

Taylor, J. B. (2000). Using monetary policy rules in emerging market economies. Stanford, CA: Stanford University.

Taylor, J. B. (Ed.) (1999). Monetary Policy Rules. Chicago: University of Chicago. http://dx.doi.org/10.7208/chicago/9780226791265.001.0001

Woglom, G. (2003). How has inflation targeting affected monetary policy in South Africa? The South African Journal of Economics, 71(2). http://dx.doi.org/10.1111/j.1813-6982.2003.tb01314.x

\section{Copyrights}

Copyright for this article is retained by the author(s), with first publication rights granted to the journal.

This is an open-access article distributed under the terms and conditions of the Creative Commons Attribution license (http://creativecommons.org/licenses/by/3.0/). 